\title{
Corrigendum: Enhancing resilience to landslide disaster risks through rehabilitation of slide scars by local communities in Mt Elgon, Uganda
}

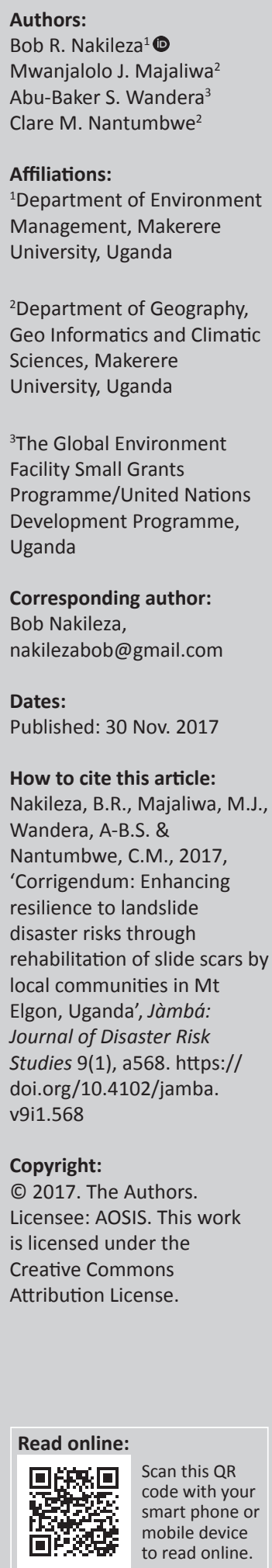

\section{Copyright:}

(C) 2017. The Authors.

Licensee: AOSIS. This work

is licensed under the

Creative Commons

Attribution License.

In the version of this article initially published, Mwanjalolo J. Majaliwa's first name was misspelled as 'Mwajalolo' and Abu-Baker S. Wandera's first name was misspelled as 'Abu'. The third affiliation was changed and updated to 'The Global Environment Facility Small Grants Programme/United Nations Development Programme, Uganda'. The errors have been corrected in the PDF version of the article. The authors apologise for any inconvenience that this omission may have caused. 